\title{
The Coming Age Of Electronic Medical Records: From Paper To Electronic
}

Naveen Malhotra, Eckerd College, USA

Marlieta Lassiter, Baycare Health System, USA

\begin{abstract}
Medical records, first developed in the fifth century, have remained virtually unchanged until the explosion of new technology in the mid-1960's. The National Space and Aeronautics Administration's development of computerized patient record (CPR) brought life to the electronic medical record (EMR) industry. Preventable deaths due to medical errors drew the attention of public and health care professionals to the need for increased patient safety and improved quality measures in medicine. With health care costs compromising 16-17\% of the U.S. Gross Domestic Product, Congress passed legislation to financially support providers to adopt electronic medical record (EMR). As a result, future efforts will focus on the sharing of information among all health care stakeholders. Across the world, governments, technology companies, and care providers are collaborating efforts to make the EMR a reality.
\end{abstract}

Keywords: Electronic Medical Records; Electronic Health Records; Electronic Patient Records; Electronic Hospital Records; Electronic Physicians Records; Electronic Surgeon's Records

\section{INTRODUCTION}

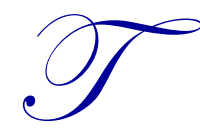

he first known medical record was developed by Hippocrates, who envisioned two goals: 1) a medical record should accurately reflect the course of disease and 2) it should indicate the probable cause of disease. During the Roman Empire, several saints opened facilities to care for the orphans, sick, or crippled. Some of those names remain with us today - St. Helena, St. Basil, and St. Jerome (Lyons, 1987). Arabic invasions and comingling of cultures created a culmination of new ideas for human preservation and treatment. The Arabs were responsible for the establishment of pharmacy and chemistry as sciences (Lyons, 1987).

During the $18^{\text {th }}$ and $19^{\text {th }}$ centuries, healers began to render care in formal settings. The Charity Hospital infirmary of Paris was a famous care center (Lyons, 1987). Etchings and paintings became the first medical records. The medical record today is a comprehensive health record, often maintained in electronic format. Older medical personnel are struggling with the new technology their younger counterparts use with ease.

Electronic medical records are reshaping health care systems. It is a quiet revolution that the patient doesn't always relate to his or her care experience. World health organizations have created the foundation to improve quality and longevity of life that few non-medical personnel understand.

\section{ADOPTION OF EMR}

The introduction of the Medicare program in the U.S. created a massive repository of beneficiary records, large processing centers, the need for electronic records, claim processing, and storage of beneficiary health information. The cost to store and subsequently retrieve past paper medical data became quite significant. Often, past medical records were stored off site and lack of immediately available data led to a delay in patient care and services.

The Kennedy administration awarded grants to private corporations to develop computer applications to manage patient care. Engineers spent many years analyzing the operational flow of data at a pilot hospital. 
Academic medical centers (AMCs) were among the pioneers in adopting automated health records. These early EMR projects included:

- $\quad$ Composite Health Care System (CHCS) - the Department of Defense's clinical care patient record system used worldwide

- $\quad$ De-Centralized Hospital Computer Program (DHCP) - developed by the Veteran's Administration

In the 1990's, the terminology changed for health care records from computerized patient record (CPR) to electronic medical record (EMR) and began to incorporate outpatient and ambulatory records. With the explosion of large scale communication networks, personal computers, and servers, the private sector has emerged with new ways to serve the medical community.

The World Health Organization (WHO) began promoting health care doctrine around the world and directing international health care funds to disadvantaged populations and disease outbreaks. The International Classification for Diseases (ICD) program began a system to track diseases of the world. Following this health care tracking procedure, the American Medical Association developed the Current Procedural Terminology (CPT) system in 1966 to describe surgery procedures in a numeric system similar to ICD-CM. This coding system expanded to all care categories. Additional coding systems were developed to describe health care procedures, medicines, and skilled diagnostic care. These coding systems make the medical EMR a viable analytic tool for care tracking and health care reimbursement models. In addition, the codes provide medical statistics and help track patient EMR between health care providers.

An additional part of the Electronic Health Record - or EMR - was the development of the Uniform Billing system. Without automated claim processing, the reimbursement model could not work electronically. The Health Insurance Portability Accountability Act of 1996 (HIPAA) mandated Electronic Data Interchange (EDI). These data standards allow for uniform electronic billing.

\section{PATIENT SAFETY IMPERATIVE}

Until the mid-1960's, a patient's medical record contained the medical and treatment history of the patient as a paper record. There are, however, many documented disadvantages to a paper chart, such as misplacement of key medical information, incomplete records, and expensive maintenance. Other common issues include the time wasted by all clinicians in gathering a patient's medical history, illegible handwriting, resulting in incorrect tests and studies being ordered, and thus incorrect medications being administered to the patient. In addition, certain laboratory tests and diagnostic study results, such as blood gases, radiology results, electrocardiogram (EKG), and electroencephalograms (EEG), are stored in various repository systems that may or may not feed data to the patient's legal medical record. By the time the paper copy of the valuable information is printed and placed with the paper medical record, critical medical decisions impacting patient care and safety could be based on incomplete medical history and/or data.

Physician practices and outpatient clinics were early adopters of the EMR. A study published by the Institute of Medicine in 1999 entitled "To Err is Human" detailing medical errors, galvanized the public and health professionals in all clinical care settings. According to this report, up to 98,000 individuals die each year in U.S. hospitals from preventable mistakes. "Before then, providers, health care organizations, and policymakers lacked the understanding and incentives to generate the changes in culture, systems, training, and technology to improve safety" (Wachter, 2004). The report highlighted, among other issues, the potential for communication problems between members of the health care team. As the tools of medicine became more powerful and technologically sophisticated, highly specialized teams were needed to deliver care. Often these teams included more than a dozen physicians, nurses, respiratory therapists, pharmacists and others contributing to deliver patient care in the shortest time and most cost efficient manner. Yet prior to the American Recovery and Reinvestment Act of 2009, just 17\% of physicians' offices and $12 \%$ of hospitals had chosen to implement some kind of electronic medical records system. 


\section{INCENTIVES TO ALLOW ADOPTION}

The U. S. Government has pledged to invest in new technology to promote electronic medical records to reduce errors, bring down costs, ensure privacy, and save lives. The 2009 Recovery Act sets aside more than \$20 billion as federal incentive payments for doctors and hospitals adopting electronic medical records and demonstrating ways that can improve quality, safety, and effectiveness of care. The National Coordinator for Health Information Technology projects that $74 \%$ of all hospitals will be investing in health exchange services" (Goldman, 2011). To support quality patient care, improve safety, and to qualify for the incentive payments, the EMR must be standardized and structured in uniform ways so that providers can demonstrate "meaningful use" objectives. The implementation of the electronic record must include:

- $\quad$ Structured templates for physician documentation

- $\quad$ Electronic results of lab tests, radiology studies, and pharmacy medication dispensing and documentation of administration

- $\quad$ A centralized data repository

- $\quad$ Clinical decision rules and alerts

- $\quad$ Evidence-based templates for computerized physician order entry

The main goal of the Health Care and Management Systems Society (HIMSS) is to improve patient safety and quality of care. It is expected that by the year 2014, $75 \%$ of all health care information technology systems will be utilizing optimized safety and quality improvement tools. The electronic medical record is expected to become a longitudinal electronic record of patient health information generated by one or more encounters in any care delivery setting. "As EMRs automate, they have the ability to generate a complete record of a clinical patient encounter as well as to support other care-related activities, directly or indirectly via interface, including evidence-based decision support, quality management, and outcomes reporting" (HIMSS).

The Centers for Medicare and Medicaid Services, in conjunction with the U.S. National Institute of Health, have begun offering additional EMR Incentives. They require that Demonstrated Meaningful Use program and treatment of Medicare and Medicaid patients mix.

\section{EMR COST/BENEFIT PAYOFF}

Practitioners delivering services to patients understand the need for electronic management of knowledge and discipline for collecting and organizing data. Alignment of information technology with the strategic business decisions of a medical facility are now viewed as a necessary cost of doing business. Earlier, nobody wanted to pay for information exchange, but now there is general acceptance to exchange information and coordinate care because the business rationale demands it (Goldman, 2011). Various stakeholders, including patients, families, health care providers, employers, and insurance payers - including the government - recognize the increased efficiency and effectiveness of an EMR and realize the competitive advantage associated with it.

A recent American Hospital Association survey found that the median annual capital investment on information technology was over $\$ 700,000$ and represented 15 percent of all capital expenses. For those entities with more advanced systems, implementation of the EMR across the entire network costs upwards of a \$1billion.

\section{BARRIERS TO ADOPTION}

In the hospital environment, one of the greatest deterrents to adoption of an electronic record is the lack of interface with other existing systems that collect and report patient care data. Vishwanath \& Scamura (2007) identified core barriers to be standardization and inoperability, in addition to technical and cost/benefit issues. Other obstacles include reluctance by some patients to believe that electronic medical records are more secure than paper records. Nonetheless, it appears that the push to encourage EMR use is here to stay. Eligible professionals who have not already adopted EMRs should begin to take advantage of the financial incentives (Millsaps \& Gotleib, 2011). HIPAA mandates security and privacy of protected health data, as well as improved efficiency and effectiveness of the nation's health care system, by encouraging the widespread use of electronic data interchange. EMR systems 
provide enormous potential to share, analyze, and present data in ways that were never possible before. These benefits will not be reached until the system designers understand how clinicians work and think. Most of the technical people working in design have training based in the financial world and are trying to use paradigms that do not sufficiently enhance clinician efficiency. As the systems improve the ability to draw data from multiple sources and present it to the clinicians in new ways, the benefits can be exponential. However, there is also the risks that poorly designed systems will impose unnecessary burdens on clinicians, degrade their performance and distract them from patient care.

\section{FUTURE IMPLICATIONS AND CONCLUSION}

EMR's are application environments composed of the clinical data repositories, clinical decision support, controlled medical vocabulary, order entry, computerized provider order entry, pharmacy, and clinical documentation applications. This environment supports the patient's electronic medical record across inpatient and outpatient environments and is used by health care practitioners to document, monitor, and manage health care delivery within a care delivery organization (CDO). The data in the EMR is the legal record of what happened to the patient during their encounter at the CDO (Garets, 2006). Leveraging technology, such as the Continuity of Care document, allows the patient and health care providers access to medical information that spans episodes of care.

The goals of Hippocrates are still appropriate. The medical record should not only reflect the course and cause of the disease, but electronic medical records systems should also provide additional functionality. Interactive alerts to clinicians when ordering tests, studies, and medications can reduce medical errors. Interactive flow sheets, capturing up to the minute monitoring of blood pressure and heart rate can reduce delays in treatment. Continuing the goal to make processes digital and connected, as well as delivering these capabilities to the health care organizations, will further improve the quality, safety, and efficiency of health care.

Currently, most clinicians and hospitals are at "the end of the beginning" of electronic medical record implementation. As the systems mature, clinical users become involved in the design and implementation. These improvements will allow data collection to become a by-product of the process-administration of medication which, in turn, can be integrated with billing, inventory, and the electronic medication administration record. The goal of supporting a robust exchange of information among stakeholders in the medical community seems to be on track.

Massive mainframe-integrated computer systems, PC tablets, hand-held PC's, and mobile smart phone applications are all creating additional layers of EMR information.

Networking technology and infrastructures are changing rapidly to adapt additional data pathways. Today, there are over 40,000 medical applications available for smart-phone downloads and tablets. The U.S. Food and Drug Administration regulates the mobile device industry, along with other government agencies, and the sheer volume of device applications is creating a backlog (Goldman, 2011).

The technology revolution has changed health care systems across the world, and our lives, in ways we may not even comprehend. The EMR is a reality embraced by government hospitals, health care providers, patients, and families. Today, patients can have a prescription printed in the doctor's office, receive a condensed printed copy of medical record for travel purposes, load health information on their smart phone, and access their medical records on the internet. Patient access to the electronic health record/EMR is creating a new level and dimension to health care. Yesterday's science fiction is certainly a partial reality today.

\section{AUTHOR INFORMATION}

Dr. Naveen K. Malhotra is the Professor of Management \& Finance at Eckerd College. He has widely published in the area of lifelong learning, finance, and international business issues. He has taught at Eckerd College for over 20 years. As the Sam M. Walton Free Enterprise Fellow at Eckerd College, he directs the highly successful Students in Free Enterprise service-learning chapter. E-mail: malhotnk@eckerd.edu 
Marlieta (Marty) Lassiter graduated from Tarpon Springs Senior High and Eckerd College. She has over 30 years of management experience in hospitals, collection agencies, and a billing/consulting firm. She attained her AAHAM Certified Revenue Cycle Executive (CPAM) certification in 1996. In 1996 she joined her current employer BayCare Health System. She is the AAHAM Florida Sunshine Chapter Treasurer and on the Education Committee. Other interests include volunteering for the Pasco Mental Health Foundation, Everest University PAC, and a political executive committee. Marty has written professional articles and edited a textbook. E-mail: mahlotnk@eckerd.edu (Corresponding author)

\section{REFERENCES}

1. Anderson, D., \& Dunphy, R. (2005). The patient financial services resource guide. AAHAM-Certification, Fairfax.

2. Biolchini, A. (2012, August 14). Smartphone app, electronic portal to allow U-M Health System patients more access to records. Ann Arbor News Business Review. Retrieved from http://annarbor.com/news/ smart-phone-app-electronic-portal-to-allow-u-m-patients-to-access

3. CPT@Process How a Code Becomes a Code. American Medical Association. (n.d.). Retrieved from http://www.ama-assn.org/ama/pub/physician-resources/solutions-Managing-your-practice/coding-billinginsurance/cpt/cpt-process-faq/code-becomes-cpt.page

4. Garets, D., \& Davis, M. (2006, Jan. 26). Electronic medical records vs. electronic health records; yes, there is a difference. Retrieved from https://www.himssanalytics.org

5. Goldman, D. (2011, November 18). National electronic health records network gets closer. CNN Money. Retrieved from http://money.cnn.com/2011/11/18/technology/electronic_health_records/index.htm

6. Holland, E., Kahn, J., Cullen, T., \& Lyon, J. (2010, August 18). CMS-EHR Incentive Programs- The Medicine Dish. United States Government- National Institute of Health. Retrieved from http://videocast.nih.gov/launch.asp?16077

7. Lyons, A. S., \& Petrucelli, II, R. J. (1978). Medicine an illustrated history (1987 ed.). New York: Abrams. Millsaps, W., \& Gotleib, D. (2011). Medical Economics, 88, 20.

8. Romano, P. S., Hussey, P., \& Ritley, D. (2010, May). Selecting quality and resource use measures: A decision guide for community quality collaboratives. (Agency for Health care Research and Quality; AHRQ Publication No. 09(10)-0073). Rockville: United States.

9. Tamny, J. (2010, Feb 1). Health Care: 16\% of GDP? New York: Forbes.com. Retrieved from http://www.forbes.com/2010/01/31/health-care-gdp-reform-opinions-columnists-john-tamny.html

10. United States. Centers for Medicare and Medicaid Services. (2010, July 13). Electronic health records at a glance. Media Release Database- List Serve News. Retrieved from https://www.cms.gov

11. United States. Center for Medicare and Medicaid Services. (2006). Reference guide for Medicare institutional providers who submit Part B claims.

12. United States. National Institutes of Health- National Center for Research Resources. (2006). Electronic health records overview. Retrieved from http://www.ncrr.nih.gov/publications/informatics/EHR.pdf

13. United States. Office of Civil Rights (2012, July). HIPAA Press Releases. Retrieved from http://www.hhs.gov/ocr/

14. United Nations. World Health Organization. (2010). World Health Organization history. Retrieved from http://www.who.int/about/history/en/index.html

15. Vishwanath, A., \& Scamura. S. (2007). Barriers to adoption of electronic health records. Sage Publications.

16. Wachter, R. M. (2004, Nov.). The end of the beginning: Patient safety five years after 'to err is human. Retrieved from http://www.creighton.edu/fileadmin/user/ipe/docs/Err_is_Human_11-2004.pdf

17. Zaroukian, M. H. (2010). EMR cost- benefit analysis: Managing ROI into reality. US Health care Efficency Index - National Progress Report 2010, Nashville: Emdeon Business Services. 
\begin{tabular}{ll} 
International Journal of Management \& Information Systems - Second Quarter $2014 \quad$ Volume 18, Number 2 \\
\hline
\end{tabular}

NOTES 